\title{
Displaying Annotations for Digitised Globes
}

\author{
Mátyás Gede, ${ }^{\mathrm{a}}$ Anna Farbinger ${ }^{\mathrm{a}}$ \\ ${ }^{a}$ Department of Cartography and Geoinformatics, Eötvös Loránd University, Budapest, Hungary; saman@map.elte.hu, \\ farbianna@gmail.com
}

\begin{abstract}
Thanks to the efforts of the various globe digitising projects, nowadays there are plenty of old globes that can be examined as 3D models on the computer screen. These globes usually contain a lot of interesting details that an average observer would not entirely discover for the first time. The authors developed a website that can display annotations for such digitised globes. These annotations help observers of the globe to discover all the important, interesting details. Annotations consist of a plain text title, a HTML formatted descriptive text and a corresponding polygon and are stored in KML format. The website is powered by the Cesium virtual globe engine.
\end{abstract}

Keywords: Digitised globes, Annotations, Cesium

\section{Introduction}

Publishing digitised old globes on the internet is a great way to protect and in the same time to disseminate this special branch of cartographic heritage. In the last decade several projects were aiming this task, e.g. the Virtual Globes Museum (Gede and Márton, 2008) or the Czechish globe collection at http://chartae-antiquae.cz (Talich et al., 2015). Making the virtual copies of old globes available to general public however, is only the first step and it opens the door to several further possibilities where these digitised globes are simply a new type of data or media to use. Such possibilities are custom collections of globes, available e.g. in the Virtual Globes Museum (Gede et al., 2013), the comparative analysis of the content of different globes (Márton et al., 2011).

Globes may contain various interesting details that are not necessarily catching the eye of a casual observer. There- fore, it is sometimes useful to supplement a globe with geo-tagged annotations: descriptive texts linked to specific points/areas of the globe surface. These annotations are an additional layer of information, which can guide the observers of the globe through the interesting parts.

\section{Creating annotations}

Globe annotations consist of two parts: the descriptive text and the reference geometry (a point or line or polygon). These type of data can easily be created and edited by most of GIS software. Maybe the most obvious solution for this task is using Google Earth or other similar geobrowser: the imagery of the old globe can be loaded as ground overlay, and user can create various placemarks and/or lines, polygons and also add the corresponding descriptive text (Fig. 1). The annotations then can be saved and stored as KML or KMZ files. The only disadvantage of using Google Earth for creating annotations is that polygons clamped to the ground will always be hidden under any ground overlays. Therefore the height of polygons should always be set to some definite value during editing in order to see them. It is also advisable to set some transparency to polygons to see the underlying globe map.

Descriptions can be plain text, as well as (as the KML format supports it) HTML formatted text.

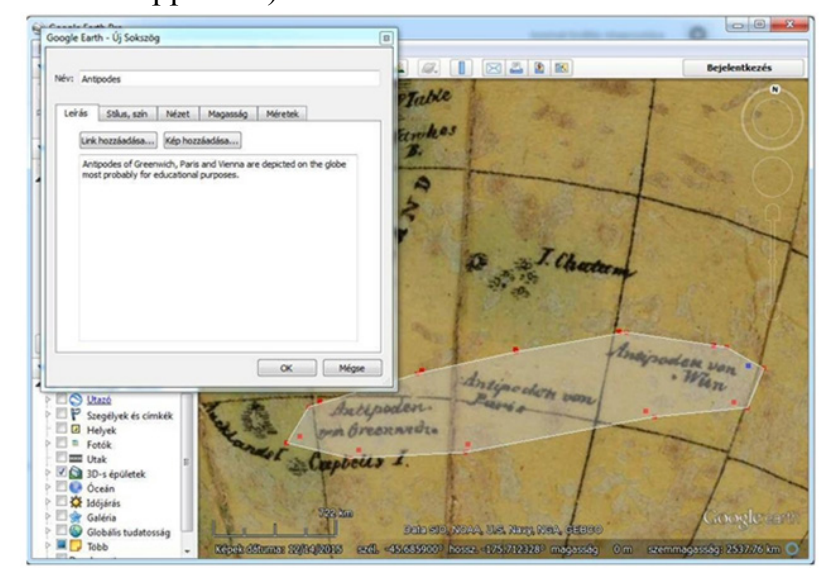

Fig. 1. Creating annotations in Google Earth.

\section{Displaying annotations}

Once we have a set of annotations for a given globe, we need a solution to display the globe content and the annotations together. A website (http://terkeptar.elte.hu/vgm/annot/) was developed for this task as a Bachelor thesis (Farbinger, 2016). The site is powered by the open source WebGL-based virtual globe engine called Cesium (Cozzi, 2013). This is an excellent tool for this task as it is capable of displaying various $\mathrm{KML} / \mathrm{KMZ}$ files either containing imagery or vector data. The base globe imagery is provided to the viewer as an URL of a KMZ file containing the globe map as a set of ground overlays, while another URL points to a KML or KMZ file with the annotations. The program parses the annotations and not only adds them to the virtual globe but also creates a clickable list of them, facilitating the navigation especially in cases when there are several annotations on a globe. 
The reference polygons of annotations are displayed of totally transparent (therefore invisible) on top of the globe map imagery, but they are turning into semitransparent surfaces if user moves the mouse over them (Fig. 2). This way the polygons don't disturb the general view of the globe, but user will be aware of the existence of an annotation when examining the corresponding part of the globe.

When the user clicks on a reference polygon, the corresponding description appears in a popup window. The same thing happen if any item in the right-hand list of the annotations is clicked. In this case the globe is also rotated to the corresponding polygon.

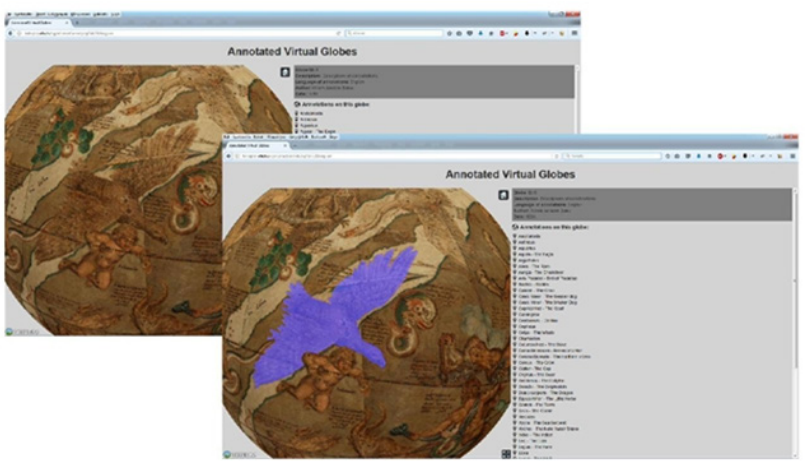

Fig. 2. Annotation reference polygons are only visible when the user moves the mouse over them

\subsection{Visualisation problems}

Although Cesium provides a very simple and straightforward way to display a KML/KMZ file, there are a few problems that had to be solved. First, a few visualisation effects - the Sun, the Moon, the stars and the atmosphere - should be turned off. As the digitised globe imagery covers all the surface of the globe, the default Bing satellite imagery can also be removed.

Some of the KMZ globe overlays are so-called "superoverlays", which is a hierarchy of image tiles in multiple resolutions to improve loading and viewing speed and reduce GPU burden (Google, 2013). This structure is implemented in KML using Region objects with LODs. Unfortunately, Cesium at this moment does not support these structures, which means that it tries to display all the tiles in various resolutions simultaneously, causing an interfered image (Fig. 3). To eliminate this glitch, the authors developed a workaround: the program examines the globe overlay $\mathrm{KMZ}$ file, and removes all low resolution tiles.
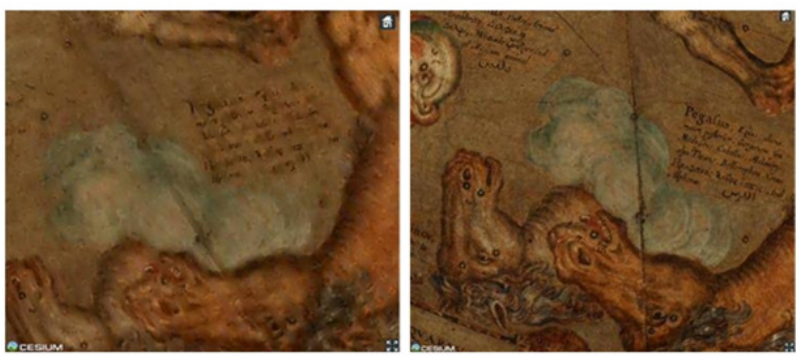

Fig. 3. Glitch when displaying super-overlay KMZs in Cesium (left), and the same overlay with the authors' workaround applied (right).

\subsection{Integrating the viewer with virtual globe} collections

The viewer website offers a very straightforward way to use with any kind of globes and annotations: the URLs of the digitised globe overlay and the annotation $\mathrm{KMZ/KML} \mathrm{files} \mathrm{can} \mathrm{be} \mathrm{passed} \mathrm{as} \mathrm{URL} \mathrm{parameters,} \mathrm{in} \mathrm{the}$ following way: http://terkeptar.elte.hu/vgm/annot/annot.php?annot_url=\{ url_of_the_annotation_kmz $\} \&$ globe_url= $\{$ url_of_the_glo be_overlay_kmz\}. The only restriction is that (as the files are loaded by JavaScript) cross-origin requests must be enabled on the hosting webserver (MDN, 2017).

The viewer also supports its embedding into other webpages with an <iframe $>$ element. In this case, an additional parameter, nobg=true can be used to make the viewer background transparent. This way it can fit seamlessly into websites with different background styles.

The website is also integrated with the Virtual Globes Museum (http://vgm.elte.hu). If a globe in the museum has any annotations associated, links to the annotation viewer appear on the globe description page (Fig. 4).

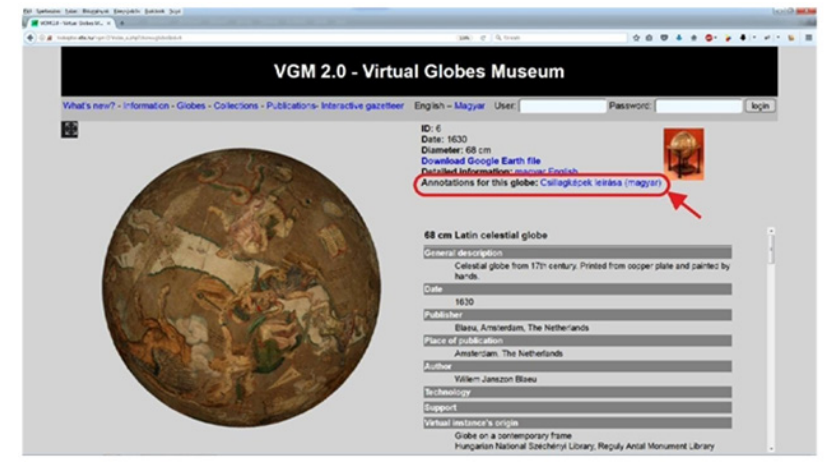

Fig. 4. If a globe in the Virtual Globes Museum has annotations, a link appears on the description page.

\section{Conclusions}

The authors created a web-based visualisation tool which displays annotations for digitised old globes. It can either be used as a standalone site or embedded into other websites.

This tool may raise the popularity of digitised globe collections as anyone can publish additional descriptive information about the content of the globes in a simple, interactive way.

\section{Acknowledgements}

This research is financed by the Hungarian National Research, Development and Innovation Office (NKFIH), grant ID: PD 111737.

\section{References}

Cozzi, P. (2013). Cesium: 3D Maps on the Web. FOSS4G NA, 05/2013.n http://cesiumjs.org/presentations/Cesium3DMapsOnThe Web.pdf

Farbinger, A. (2016). Helyhez kötött magyarázó megjegyzések virtuális glóbuszokhoz. [Georeferenced 
annotations for virtual globes.] BSc thesis, Eötvös Loránd University, Budapest. http://lazarus.elte.hu/hun/digkonyv/szakdolg/2016bsc/farbinger_anna.pdf

Gede, M., Márton, M. (2009). Globes on the Web Technical Background and First Items of the Virtual Globes Museum. In Gartner, Ortag (Eds.), Cartography in Central and Eastern Europe. Springer, Berlin, Heidelberg. (pp. 279-290).

Gede, M. Ungvári, Zs., Zentai, L. (2013). Virtual Globes Museum 2.0 - Adding the Power of Community. Proceedings of $\quad$ ICC 2013. http://icaci.org/files/documents/ICC_proceedings/ICC2 013/_extendedAbstract/174_proceeding.pdf

Google (2013). Super-Overlays. In: KML 2.1 Tutorial. $\mathrm{https} / / /$ developers.google.com/ $/ \mathrm{kml} /$ documentation $/ \mathrm{kml}$ 21 tutorial\#superoverlays

Márton, M., Plihál, K., Ungvári, Zs. (2011). Restoring Blaeu's Globes by Modern Methods. Proceedings of ICC 2011. MDN (2017). Server-Side Access Control (CORS). Mozilla Developer Network. https://developer.mozilla.org/enUS/docs/Web/HTTP/Server-Side_Access_Control

Talich, M., Ambrožová, K., Havrlant, J., Böhm, O. (2015). Digitization of Old Globes by a Photogrammetric Method. In Sluter, Cruz, Menezes (Eds.), Cartography - Maps Connecting the World. Springer Internatioinal Publishing. (pp. 249-263). 